of April last a deputation of veterinary sur. geons, accompanied by Mr. Kemble and Mr. Antrobus, the members for Surrey, waited upon Sir James Graham on the subject, and the result of that interview will form an epoch in our history, and deservedly so, when we consider that an application for a charter was made by our parent institution, about forty years ago, to the late Earl of Eldon, when lord chancellor, who dismissed it summarily, with ' You shall not have a charter.'"

Mr. Turner adds, that the interview with Sir James lasted an hour, and that he hopes for success in the application.

\section{THE ABDOMINAL AORTA TIED.}

To the Editor of Thr. La NCET.

SIR,-I send you a short notice of a case of ligature of the abdominal aorta, extracted from a letter of a non-medical friend residing at Rio de Janeiro. In the absence of a more detailed statement, it will, I doubt not, be acceptable to your readers. Yours faithfully,

\section{Peckham House, Surrey,} Nov, 21, 1842.

\section{J AMES HILL.}

The following statement is derived from an article in the Jornal de Commercio, August 7, 1842:-"On Friday, July 5th, at No. 31, Rua das Violas, the abdominal aorta was tied, for the first time amongst us, immediately above its bifurcation, without doubt the boldest operation in surgery, and carried into effect in England only by Astley Cooper and James, without any favourable result. Nevertheless, the patient, A. M. Cardozo, seemed to be overcoming the terrible consequences that it was supposed would follow. The operator was Dr. Candido Borges Monteiro. For about a week after the operation the patient was seemingly getting better, but they could not consider him out of danger for at least twenty days,"-not to live, however, for he died on (I think) the 15th. The body was taken next day to the School of Medicine, and examined by the operator, in presence of a number of medical men, when they found that everything had been rightly performed, the case only affording another proof that the result must necessarily be fatal.

\section{MR. WORMALD'S TREATMENT OF}

\section{OPHTHALMIC AFFECTIONS.}

To the Editor.-Sir: In cases of intolerance of light with inflammation, or a granular state of the conjunctiva, ulceration or opacity of the cornea, and other affections of the eye, besides the appropriate constitutional treatment, I have been for years in the habit of lightly applying, with the greatest benefit, the nitrate of silver, in substance, externally, to the lids, with the view of allaying the morbid susceptibility of that portion of the fifth pair of nerves supplying these parts. Even in intolerance of light, where other structures are involved, sometimes considerable benefit is experienced by this harm. less and simple treatment.

I am induced, thus briefly and publicly, to announce the fact, from reading a paper in The Lancet, by Dr. Hocken, entitled, "A New and Improved Plan," \&c. \&c. Now, as Dr. Hocken has, with other pupils, been in the habit of seeing my practice at the out-patients'-room at St. Bartholomew's Hospital, I think it only justice to myself to state that this treatment has been there successfully employed, not only in "slight ophthalmic affections," but in many severe ailments, and although decidedly "an improved plan," it is certainly not " new," either to my pupils or to your obedient servant,

Bedford-row, Nov. 19, 1842.

\section{THE BAT CLUB.}

The meeting of this club was held at the Hole-in-the-wall, on Wednesday evening last. As it was an "open meeting," pro. digious numbers of practitioners and students attended, as members and visitors, for the purpose of hearing from Sir James GraHaM the exposé of his plan of medical reform. Sir HENRY Halford occupied the chair, and Sir Robert Peel had a seat at his right hand. The greatest excitement prevailed, and the proceedings, according to the laws of the association, were adjourned at 11 o'clock precisely. We shall furnish a full report of the incidents of this interesting scene in the next Lancet. Sir Henry HaLFORD, at one period of the meeting, seemed to be much alarmed, and when asked what he thought the result of the agitation of the question of medical reform would be, he answered, submissively, that it was impossible to foretell, adding, that he endeavoured to protect himself as well as he could against personal calamity, by adopting for his motto, "Cede Deo."

\section{CORRESPONDENTS.}

A Staffordshire Attorney.-If Dr. Dehane is a practising physician, is not Mr. Phillips a practising solicitor? If the one has patients, has not the other clients? If the candidates be men of honourable reputation, objection to either of them, on the ground that they may be personally interested be- 